\title{
Chromosome Studies in Cyperaceae,
}

\section{Chromosome Number and Pollen Development of Fimbristylis. ${ }^{1)}$}

\author{
By
}

\section{Nobunori Tanaka.}

With 9 Text-figures.

Received September 15, 1939.

Chromosome studies of Fimbristylis are helpful in shedding light on the remarkable aneuploidy in Cyperaceae. Recently, certain cases of polyploidy with demonstrable examples have been found in other genera, and in the present paper a probable case of polyploidy will also be reported. Heretofore, there have been no reports of cytological studies made on this genus with the exception of a short note by the writer (1937). He reported one haploid chromosome number of Fimbristylis subbispicata NEES et MEY as $\mathrm{n}=5$, which along with that found in Heleocharis is the smallest chromosome number seen in the Cyperaceae.

\section{Material and Methods.}

The materials used in the present investigation were collected in various districts in the central provinces of Japan. In most cases, the inflorescences were fixed with a 3:1 absolute alcohol-glacial acetic acid mixture in their habitats. As the flowering season is in summer, fixation in the field sometimes showed bad results. In such eases, the plants collected were planted in a water-pot and the inflorescences were fixed after being placed in an ice-box in which the air temperature was kept at ca. $18^{\circ} \mathrm{C}$, while the room temperature ea. $30^{\circ} \mathrm{C}$. These fixed materials were preserved in $75 \%$ alcohol after being washed in $95 \%$ alcohol. The anther sacs were plucked from these inflorescences out with needles under the magnifying glass, and stained with either aceto-carmine or light-green (80\% alcohol solution). The cover-glass was sealed with a $2: 2: 1$ vaseline, lanoline and paraffin mixture devised recently in our laboratory and called "Valap" by taking a proportionate number of letters from the names of the ingredients.

1) Contributions from the Divisions of Genetics and of Plant-Morphology, Botanical Institute, Faculty of Science, Tôkyô Imperial University, No. 235. 


\section{Observations.}

Chromosome number.

Chromosome numbers are summarised in table 1. Brief descriptions will be given.

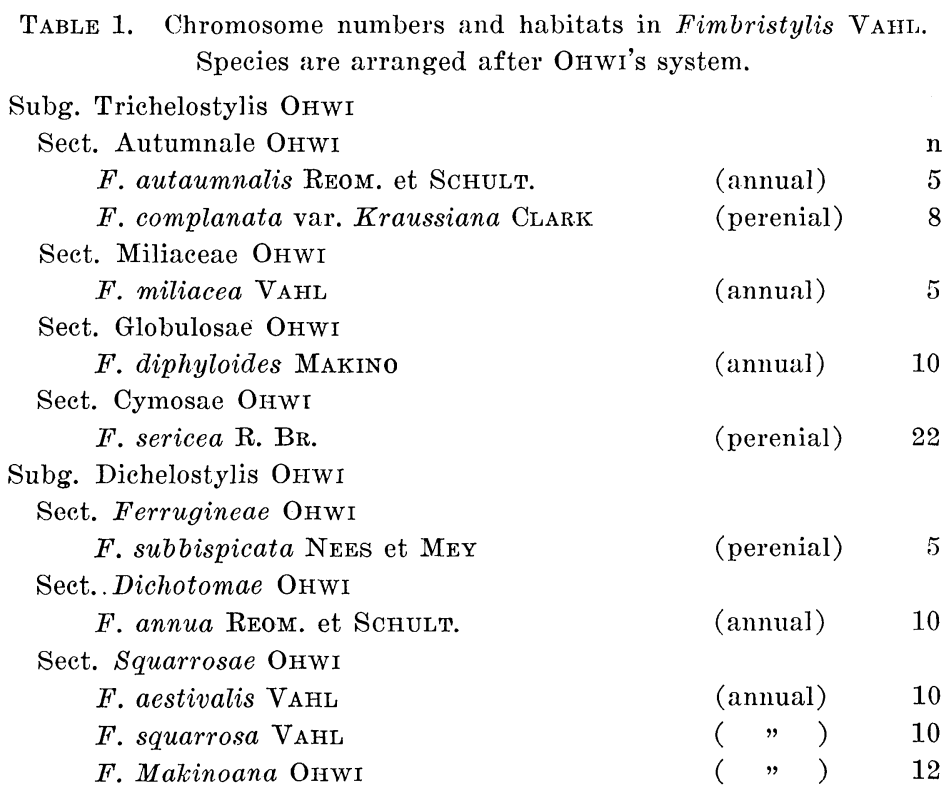

Fimbristylis autumnalis Roem. et Schult. (Jn. ${ }^{1)}$ Hime-tentuki). $\mathrm{n}=5$. (fig. 1.). Four bivalents of about the same size and one smaller one have been observed in the first meiotic metaphase. This species, showing no aneuploid plants, was collected, in the following districts; namely, Karuizawa and Huzimi in Nagano Prefecture, Hakone and Kanazawa in Kanagawa Prefecture, Musata in Tiba Prefecture and at several places in the vicinity of Tôkyô.

F. miliacea VAHL (Jn. Hideriko). $\mathrm{n}=5$. (fig. 2.). The chromosome number was ascertained in the I-M and II-M of the PMC's. Four chromosomes of about the same size and one somewhat larger one have been observed. The plants were collected in the same districts as $F$. autumnalis. . No aneuploid plants were also observed in this species.

F. aestivalis VAHL (Jn. Koaze-tentuki). $\mathrm{n}=5,2 \mathrm{n}=10$. (figs. $3 \mathrm{a}-\mathrm{f}$ ). Four chromosomes out of five are somewhat larger. In meiosis the smallest chromosome pair revealed earlier separation (figs. $3 \mathrm{~b}, \mathrm{c}$ ), and even in the

1) $\mathrm{Jn}_{\mathrm{n}}=$ Japanese name. 

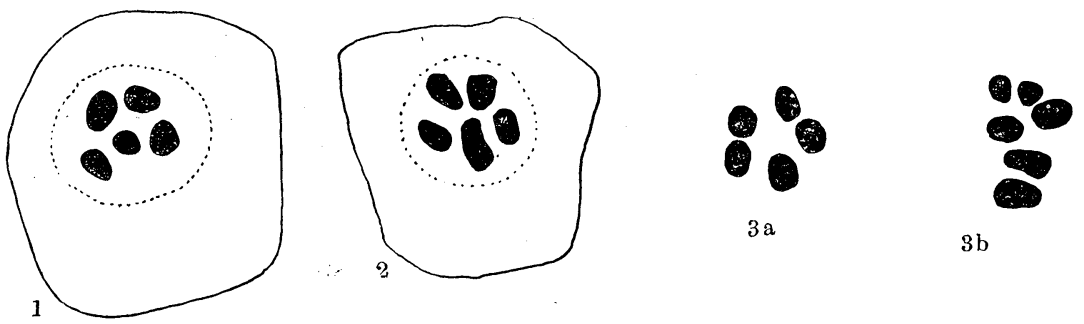

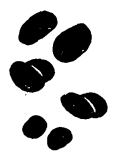

3 .

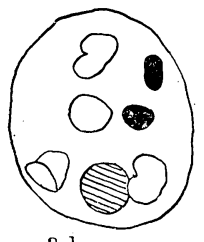

$3 \mathrm{~d}$

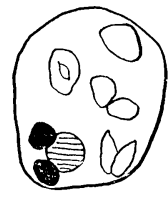

$3 \mathrm{e}$
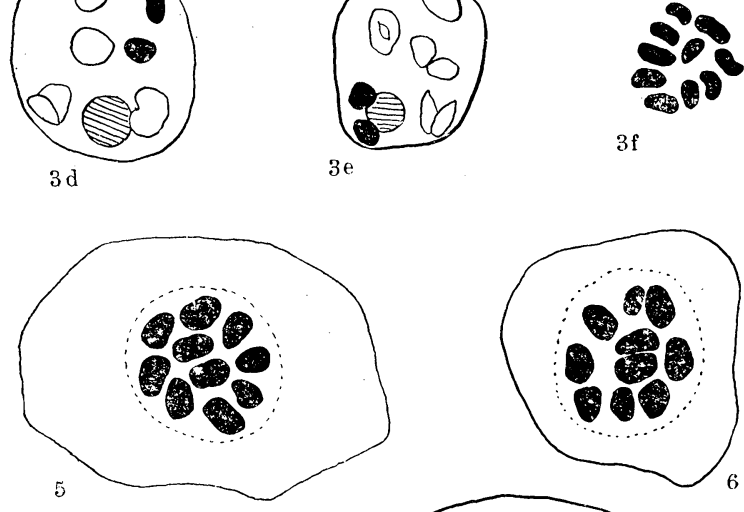

$3 \mathrm{f}$

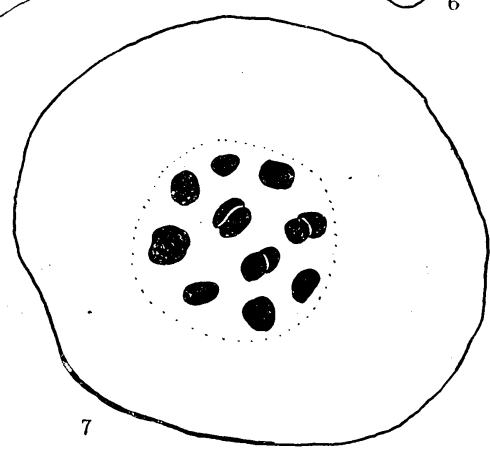

$8 b$

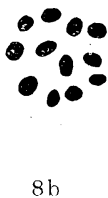

Text-figs. 1-8. Chromosomes of 7 species and 1 variety of Fimbristylis. 1. F. autumnalis, first metaphase in meiosis $(1-\mathrm{M})$, 5 รI. $_{\text {. }}$ 2. F. millacea, 1-M, $5_{\mathrm{Ir}}$. 3 a-f. F. aestivalis; a, I-M, 5 Ir. b and e, I-M, 4 Ir +2 I. d and e, diakinesis, showing early separation of a small chromosome pair. $f$, somatic chromosomes in the root-tip cells. 4. F. complanata var. Kraussiana, primary pollen nuclear division metaphase with 8 chromosomes. 5. $F$. annua, I-M, 10 Ir. 6. F. diphyloides,

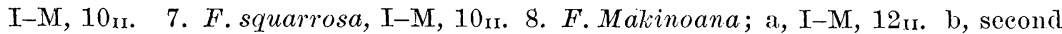
metaphase in meiosis (II-M), 12 chromosomes. $\times 2200$.

prophase the same thing was observed (figs. $3 \mathrm{~d}$, e). Therefore it may suggest the feebleness of pairing of the smallest chromosomes. Places of collection are the same as in the case of the above two species.

F. complanata Link var. Kraussiana C. B. Clark (Jn. No-tentuki). n=8. 
(fig. 4.). Eight chromosomes, two of them long, were counted in the primary pollen nuclear division. Karyotypically this variety may be of interest, as regards the joining point of the $n=5$ and $n=10$ groups. This variety was collected at the foot of Mt. Yatugatake in Nagano Prefecture.

$F$. annua Reom. et Scrult. (Jn. Tentuki). $\mathrm{n}=10$. (fig. 5.). Ten bivalents, two of them somewhat smaller than the others were counted in the I-M and II-M of the PMC's. This species was collected at Hakone and Kanazawa in Kanagawa Prefecture, Huzimi in Nagano Prefecture, Musata in Tiba Prefecture and in the vicinity of Tôkyô.

$F$. diphyloides Maxino (Jn. Kuro-tentuki). n=10. (fig. 6.). Ten bivalents, two of them large, 6 medium and 2 small, were observed in the first meiotic metaphase. Collected at Kanazawa in Kanagawa Pref., at Itinomiya and Musata in Tiba Pref. and in the vicinity of Tôkyô.

F. squarrosa VAHL (Jn. Aze-tentuki). n=10. (fig. 7.). Ten bivalents, two of them large, 6 medium and 2 small, were observed in the I-M of the PMC's. Chromosomes of this species are much smaller than those of $F$. diphyloides. Collected at Karuizawa and Huzimi in Nagano Prefecture, Yamanaka in Yamanasi Pref., Hakone and Kanazawa in Kanagawa Pref., and in the vicinity of Tôkyô.

F. Makinoana Orwi (Jn. Meaze-tentuki). $\mathrm{n}=12$. (figs. $8 \mathrm{a}, \mathrm{b}$.). In the first and second meiotic metaphases, 12 chromosomes, 4-6 of them smaller ones, were observed. Collected at Karuizawa in Nagano Pref., at Yamanaka in Yamanasi Pref., and at Tomioka in Kanagawa Prefecture.

F. sericea R. BR. (Jn. Birōdo-tentuki). $\mathrm{n}=22$. (figs. $9 \mathrm{a}, \mathrm{b}, \&$ f.). This has the largest chromosome number of the species so far investigated in this genus. Twenty-two small chromosomes were counted in the I-M, II-M, and in the primary pollen nuclear division metaphase. This species was collected on the dune at Kugenuma in Kanagawa Pref., and at Itinomiya in Tiba Prefecture.

Pollen development.

Pollen development was investigated in $F$. sericea R. BR.. The first meiotic division takes place, generally, either along or somewhat obliquely to the long axis of the PMC's which are wedge-shaped (fig. 9 a). It results in two daughter nuclei with no septum between them. The second division proceeds normally soon after the first interkinesis and quartet nuclei have been formed (figs. $9 \mathrm{~b}-\mathrm{d}$.). The quartet nuclei are of the same size when they are first formed but soon one of them which is situated in the outermost position in the PMC grows larger and the rest are pushed to an inner corner of the PMC (fig. 9 d.), the former becoming a pollen nucleus and 
the latter finally degenerating. Thus in Fimbristylis only one pollen grain, instead of the four usual in Angiosperms, arises from a PMC. This is in conformity with the observations made in the case of other genera (cf. Tanaka, 1939 b, c \& d, etc.), Carex, Scirpus and Heleocharis. Although the size difference becomes marked, the quartet nuclei nevertheless get into the next nuclear division simultaneously. The volume ratio of the pollen nucleus and the degenerating nuclei in diakinesis of the pollen nuclear division is approximately equal to $8: 1$. A generative and a vegetative nuclei are produced by the primary nuclear division which takes place in the inner space of the PMC along the long axis of the pollen grain (fig. 9 e.). Genetrative cell-plate formation such as was found in Carex and Scirpus has also been observed (figs. $9 \mathrm{~g}, \mathrm{~h}$.), but in Fimbristylis the generative cytoplasm soon penerates into the vegetative plasm and the border becomes faint; the nucleus alone seems to remain visible and the cytoplasm appears
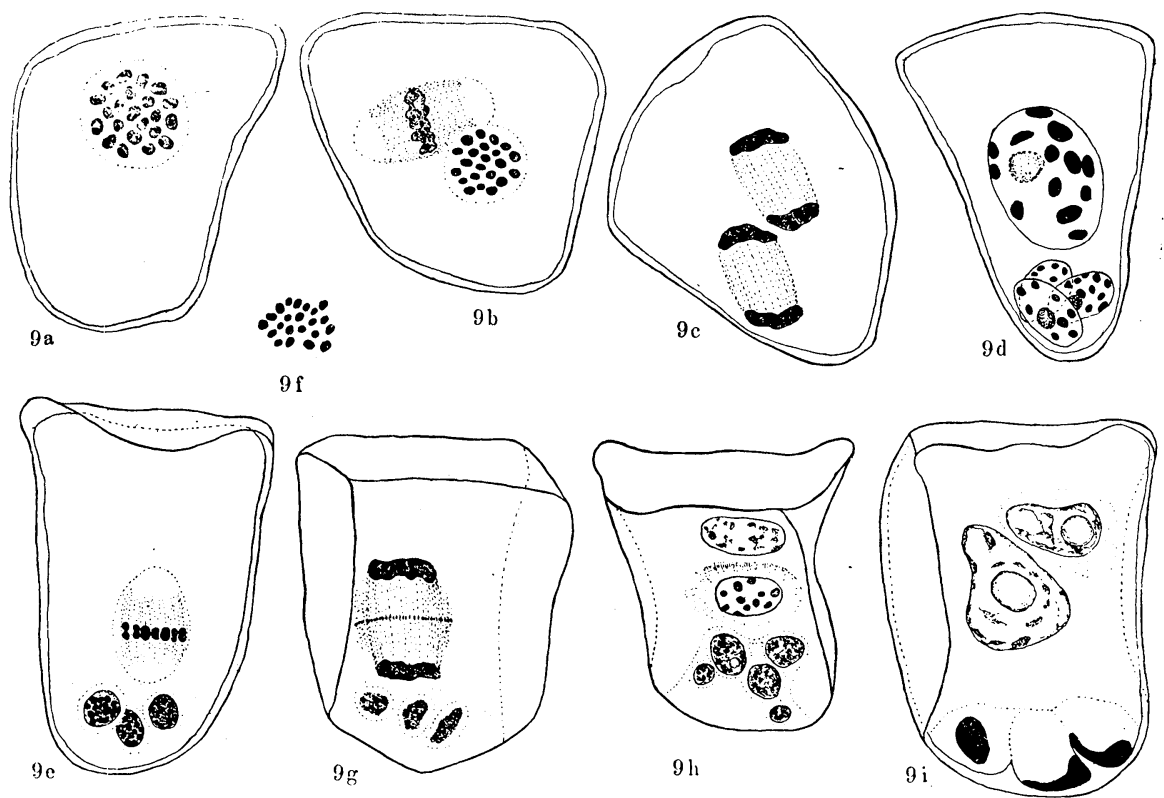

Text-figs. $9 \mathrm{a}-\mathrm{i}$, pollen development of $F$. sericea. a, I-M, 22 II. b, II-M, 22 chromosomes. e, second telophase. d, diakinesis of the pollen nuclear division. e and $f$, metaphases in side view (e) and in polar view (f), of the primary pollen nuclear division, in the latter 22 chromosomes seen. $g$, telophase of the pollen division, the phragmoplast is seen in the central region of the telophasic spindle. $h$, a generative cell-plate and a vegetative nucleus, the former is formed by the union of the phragmoplast which appears first in the central region of the telophasic spindle. i, young pollen grain, the generative cell moves peripherally; the degenerating nuclei seen in the inner corner where trace of septum formation is sen. $\times 1700$. 
to have disappeared. It seems, however, highly probable that this is due to inadequate technic rather than to actual absence of the generative cytoplasm (compare the cases known in the Angiosperms). The three small nuclei in the corner proved to possess less power of dividing by themselves than in the cases of Carex and Scirpus. There were rare cases of irregular division, however, more than three micronuclei having been produced in the corner (fig. $9 \mathrm{~h}$.). Whenever more than three micronuclei were produced, they formed three restitution nuclei and in due time when the generative cell reached the outermost position in the PMC, they adhered to the inner membrane to degenerate (fig. $9 \mathrm{i}$.).

In the mode of septum formation between the pollen nuclei and the three micronuclei in the corner as well as that the septa among the three micronuclei in the corner, differences were seen among the three genera, Carex, Scirpus and Fimbristylis. In Fimbristylis hardly any clear septa formation was observed, while in Carex and Scirpus the reverse was the case. However, when stained with light-green, the pollen cytoplasm stained deeply, while that belonging to the three micronuclei in the corner stained very faintly, so that a clear border was distinguished.

The generative cell moves peripherally and finally becomes situated in the outermost position in the PMC. The three micronuclei in the corner rarely divided by themselves, as stated above, but when they did there resulted several micronuclei which seemed to form restitution nuclei; while when the generative cell became situated in the outermost position of the pollen grain these three micronuclei were pushed up to the membrane. Even at this stage hardly any clear septa were formed between the pollen nuclei and the three micronuclei as well as among thesé latter themselves. Continuous granules which were arranged in place of the septa were, however, observed, and at the inner cell membrane clear traces of septum formation were also observed (fig. 9 i.).

\section{Comments.}

The genus Fimbristylis has been divided into four subgenera, i.e. subg. 1 Echinolytrum Oнwi, subg. 2 Abildgaardia OHwI, subg. 3 Trichelostylis OHwi and subg. 4 Dichelostylis OHwi (OHwi, 1938). The species and varieties used in the present investigation belong to the last two subgenera.

As seen in table 1 , five haploid chromosome numbers, i.e. $n=5,8,10$, 12, 22 have been found in this genus. In the subgenus Trichelostylis four haploid chromosome numbers, 5, 8, 10, 22, and in the subgenus Dichelostylis three haploid chromosome numbers, 5, 10 and 12, have been found. The fact that in both subgenera two haploid chromosome numbers, 5 and 10 , occur with high frequency $(80 \%)$ may suggest the presence of one basic 
number $5(b=5)$ and consequently of a polyploid series with $b=5$. In view of the fact that the present data are so meagre it may certainly be premature to decide that the basic number in Cyperaceae is 5; however, it is not difficult, reflecting on the following aspects, to consider 5 as one of the most likely basic numbers possible. W WNScher (1934) suggested 4 or 8 as the probable basic number in Cyperaceae, especially in Carex, but at that time the haploid chromosome number 8 was the smallest one to have been found. In Gramineae, the nearly related family, $b=5$ has been estimated by FuoviK (1938) as an original basic number. According to WULFF's opinion (1939), several relationships have been found in cytological aspects between Cyperaceae and Juncaceae, and in the latter family two basic numbers $\mathrm{b}=5$ and 3 have been established. As was already reported by the writer (1939 e) as well as by WuLFF (1939) in Iteleocharis, a closely related genus in Cyperaceae, notwithstanding the presence of aneuploidy even within a species which is the common characterestic feature throughout Cyperaceae (ef. TANAKa, 1937, $1939 \mathrm{a}, \mathrm{d}$, e, ete.), a polyploid series with basic number $5(5,10,15)$ has been found. Anc the last fact will furnish a reasonable basis for the above suggestion. Recently, also in Carex, as reported by the writer (1939 a,d), a clear polyploid relation has been found, and some prospect seen of a reasonabie explanation for the extraordinary aneuploidy in Cyperaceae. More recentiy HeILionn (1939) has reported the same possibility, and from the distribution frequency of the chromosome numbers in Carex he has presumed the basic number of the genus to be 7 . The writer has found diploid and autotetraploid plants in Carex siderosticta $\mathrm{H}_{\mathrm{ANCE}}$, the former having 4 large and 2 small chromosomes in a haploid set; accordingly from the karyological point of view a basic number 5 may also exist in Carex, and the haploid chromosome number of this species $n=6$ as well as number 7 postulated by Heilions (1939) may be derivatives of the former. Consequently, in this quarter, the chromosome study in Fimbristylis and in Heleocharis has a great significance, and further studies in these genera may furnish many hints for the solution of the aneuploidy problem in Cyperaceae.

Systematically, Fimbristylis is elosely related to both to Heleocharis and Scirpus and judging from the chromosome number Fimbristylis may be the simplest and most primitive type. This appears likely also in view of its pollen development. Although the general course of the pollen development is similar in each case (cf. TANAKA, $1939 \mathrm{~b}$, c, etc.), it is possible to find some differences between them. Firstly, the three micronuclei in the former are able to divide by themselves while in the latter there is scarcely any self-division. Secondly, the mode of septum formation 
between the pollen nuclei and the degenerating micronuclei as well as between the latter themselves are also different; in Fimbristylis there is scarcely any formation of septa.

In the process of phylogenetic development in chromosome number and size it is very likely that the higher chromosome numbers have been derived from the lower ones, many instances of this having been observed (Delaunay, 1926). In Cyperaceae, only one out of the quartet nuclei which formed after reduction division in the pollen mother cell can function; this is comparable with the usual condition in the development of the megagametophyte. This condition may indicate, in the light of known cases in the Angiosperms, the existence of the most primitive possible state. And if this is true, the deficient septa formation in the PMC's of Fimbristylis should be the original condition in Cyperaceae. Furthermore, in this family, as mentioned above, only one pollen grain arises from a PMC, i.e. only one nucleus of the quartets survives; consequently the survivor will receive plentiful nutrition. Therefore, even though the survivor may be of a genetically unbalanced type it may function. It seems, however, more likely that the increasing change in chromosome number may occur more often than the decreasing one, for the unbalanced condition with excess genes will have more chances of survival than that with deficient genes. If this is correct, considering both chromosome number and the pollen development, the genus Fimbristylis is the simplest and the most primitive one in Cyperaceae.

In conclusion the writer wishes to express his best thanks to Prof. Y. Sinotô under whose direction the work has been carried out. Thanks are also due to Dr. Turama for his kindness in verifing the plants used in the present work.

$$
\begin{aligned}
& \text { Division of Genetics, Botanical Institute, } \\
& \text { Faculty of Science, Tôkyô Imp. University. }
\end{aligned}
$$

\section{Literature.}

Heilborn, O. 1939. Chromosome studies in Cyperaceae III-IV. Hereditas 25: 224240.

Delaunay, L. N. 1926. Phylogenetische Chromosomenverkürzung. Zeit. f. Zellf. u. mikr. Anat. 4: 338-364.

Flovik, K. 1938. Cytological studies of arctic grasses. Hereditas 24: 265-376.

OHwI, J. 1938. Notes on Japanese Fimbristylis. Jour. Jap. Bot. 14: 564-579.

Tanaka, N. 1937. Chromosome studies in Cyperaceae, I. Cytologia, Fujii Jub. Vol. $814-821$.

1939a. Ditto IV. Chromosome number of Carex species. Cytologia, 10: 51-58.

,$-- 1939 a$.
,-
Kükenth. ex Matsum. Jap. Jour. Genet. 15 : 153-157: 
_- 1939c. Ditto VI. Pollen development and additional evidence for the compound chromosome in Scirpus lacustris L. Cytologia, 10 (in the press).

- $1939 \mathrm{~d}$. Cytological studies in the genus Carex. (A collective review). Jap. Jour. Genet. 15: 96-104.

—_ 1939e. Aneuploidy and polyploidy in Cyperaceae. Seience (Tokyo). 9: 130-132.

—_ and Suita, N. 1939. A new sealing mixture "Valap" and a simple revise technic for aceto-carmine preparation. Bot. and Zool. (Tokyo). 7: 1449-1450.

WANSChER, J. H. 1934. The basic chromosome number of the higher plants. New Phytolog. 33 : 101-126.

WulfF, H. D. 1939. Die Pollenentwicklung der Juncaceen nebst einer Auswertung der embryologischen Befunde hinsichtlich einer Verwandtschaft zwischen den Juncaceen und Cyperaceen. Jahrb. f. wiss. Bot. 87: 533-556. 